\title{
INFLUÊNCIA GENOTÍPICA NA ABSORÇÃO E NA TOXIDEZ DE MANGANÊS EM SOJA ${ }^{(1)}$
}

\author{
José Lavres Junior ${ }^{(2)}$, Milton Ferreira Moraes ${ }^{(2)}$, Cleusa \\ Pereira Cabral $^{(3)}$ \& Eurípedes Malavolta ${ }^{(4)}$
}

\begin{abstract}
RESUMO
A toxidez de Mn pode ser um problema comum nas regiões tropicais com predominância de solos ácidos. Entretanto, variações das concentrações desse nutriente nas plantas têm sido atribuídas também a diferenças inter e intraespecíficas. $O$ presente estudo foi desenvolvido em casa de vegetação e teve como objetivo avaliar as causas de tolerância diferencial à toxidez de Mn. Os cultivares de soja [Glycine max (L.) Merrill] Santa Rosa, IAC-15 e IAC-Foscarin 31 foram cultivados em solução nutritiva (pH 5,0) com cinco doses de Mn $(2,100,150,200$ e $250 \mu \mathrm{mol} \mathrm{L}{ }^{-1}$ ). $O$ delineamento experimental foi o de blocos completos ao acaso em esquema fatorial 5 x 3 (cinco doses de Mn e três cultivares), com três repetições. Os cultivares IAC-15 e Santa Rosa exibiram sintomas visuais de toxidez. As concentrações nas folhas associadas ao excesso foram de $1.000 \mathrm{mg} \mathrm{kg}^{-1}$. Entretanto, o IAC-15 apresentou maior produção de grãos e de matéria seca da parte aérea, acompanhado pelo IAC-Foscarin 31 (intermediário) e Santa Rosa (menor produção). O maior comprimento total de raízes, as maiores produções de matéria seca de raízes e o acúmulo de Mn neste tecido, bem como a maior compartimentalização deste nutriente no apoplasto, conferiram ao IAC-Foscarin 31 maior tolerância ao excesso de Mn na solução. Há, pois, indicações de diferenças genotípicas entre os cultivares e de que vários mecanismos atuam conjuntamente na tolerância ao excesso de Mn em solução.
\end{abstract}

Termos de indexação: apoplasto, comprimento total de raízes, simplasto.

\section{SUMMARY: GENOTYPIC INFLUENCE ON THE ABSORPTION AND TOXICITY OF MANGANESE IN SOYBEAN}

Manganese (Mn) toxicity may be a constraint for crop production in acid soils of tropical regions. However, variations of Mn concentrations in plant tissues are also related

\footnotetext{
(1) Recebido para publicação em abril de 2007 e aprovado em outubro de 2007.

${ }^{(2)}$ Doutorando do Programa de Pós-Graduação em Energia Nuclear na Agricultura e no Ambiente, Centro de Energia Nuclear na Agricultura, Universidade de São Paulo - CENA/USP. Laboratório de Nutrição Mineral de Plantas, Caixa Postal 96, CEP 13400-970 Piracicaba (SP). Bolsistas CAPES e FAPESP. E-mails: jjlavres@yahoo.com.br; moraesfm@yahoo.com.br

${ }^{(3)}$ Bióloga do Centro de Energia Nuclear na Agricultura, CENA/USP. E-mail: cpcabral@cena.usp.br

(4) Professor Catedrático do Centro de Energia Nuclear na Agricultura CENA/USP. Bolsista CNPq. E-mail: mala@cena.usp.br
} 
to the genotypic differences. A greenhouse experiment was carried out to evaluate $M n$ tolerance of three soybean cultivars [Glycine max (L.) Merrill]. Cultivars Santa Rosa, IAC15 and IAC-Foscarin 31 were evaluated under five Mn rates (2, 100, 150, 200, and $250 \mu \mathrm{mol} \mathrm{L} \mathrm{L}^{-1}$ ) in nutrient solution ( $\mathrm{pH}$ 5.0). The experiment in randomized blocks was a $5 \times 3$ factorial of five Mn doses and three cultivars, with three replications. IAC-15 and Santa Rosa leaves showed visual symptoms of Mn toxicity. At toxic Mn levels in solution, the average $\mathrm{Mn}$ concentration in the leaf blades was close to $1,000 \mathrm{mg} \mathrm{kg}^{-1}$. Nevertheless, grain and dry matter in the aerial parts was higher for IAC-15 than IAC-Foscarin 31 (intermediate yield) and Santa Rosa (lowest yield). The greatest total root length and root dry matter yield, as well as root Mn accumulation and compartmentalization in root apoplast of IAC-Foscarin 31 contributes to explain differences in tolerance to the excess. There are, therefore, indications of genotypic differences among the soybean cultivars and that several mechanisms are involved in the tolerance to high Mn levels.

Index terms: apoplast, total root length, symplast.

\section{INTRODUÇÃO}

Aproximadamente $40 \%$ das terras cultivadas no mundo e acima de $70 \%$ das áreas potencialmente destinadas à agricultura são compostas de solos ácidos (Miyasaka et al., 1989). A acidificação de solos agrícolas apresenta a maior limitação para produção agrícola sustentada e pastagens em diversas partes do mundo (Clune \& Copeland, 1999). Ocorrências de desordens nutricionais em plantas cultivadas na região dos Cerrados no Brasil, geralmente, estão associadas à acentuada acidez desses solos, devido aos altos teores de $\mathrm{Al}$ e $\mathrm{Mn}$ e baixos teores de $\mathrm{Ca}, \mathrm{Mg}$ e $\mathrm{P}$ (Malavolta \& Kliemann, 1985).

O Mn é o micronutriente mais abundante no solo depois do Fe. Encontra-se em teor que varia de 20 a $3.000 \mathrm{mg} \mathrm{kg}^{-1}$, e a disponibilidade aumenta com a diminuição do pH do solo (Adriano, 2001; KabataPendias \& Pendias, 2001). Os sintomas de toxidez de Mn são amplamente relatados na literatura em diversas espécies vegetais, e as variações das concentrações de Mn nas plantas têm sido atribuídas às diferenças inter e intra-específicas, além das condições edafoclimáticas (Fageria, 2001; Moroni et al., 2003).

Os mecanismos de tolerância ao excesso de Mn têm sido associados à oxidação deste nutriente nas raízes, à restrição na taxa de absorção pelas raízes e ao transporte do excesso de Mn para as folhas, bem como à distribuição uniforme do Mn nos tecidos vegetais, à maior tolerância interna e à interação com outros nutrientes (Foy et al., 1988; Moroni et al., 2003). É absorvido na forma de $\mathrm{Mn}^{2+}$ pelas raízes e acumulado nos compartimentos do apoplasto e simplasto em três frações distintas: a forma trocável, referente ao apoplasto, está adsorvida às cargas negativas na matriz péctica da parede celular; a forma lábil, associada ao Mn localizado no citoplasma; e a forma não-lábil, referente ao Mn depositado nos vacúolos (Munns et al., 1963; Page \& Dainty, 1963; Wang, 2003).
Procurou-se identificar, no presente trabalho, as causas da maior tolerância à toxidez de Mn, se devidas à menor absorção de $\mathrm{Mn}$, ao menor transporte a longa distância, ou a ambos os fatores. Os resultados foram avaliados por meio da produção de matéria seca das plantas (parte aérea, raízes e grãos), do transporte a longa distância, das concentrações e quantidades acumuladas de Mn nas partes das plantas, da compartimentalização do Mn nas raízes e dos atributos radiculares (comprimento e superfície total) de três cultivares de soja.

\section{MATERIAL E MÉTODOS}

Dois experimentos foram realizados em casa de vegetação localizada no Centro de Energia Nuclear na Agricultura da Universidade de São Paulo, em Piracicaba-SP. Os cultivares Santa Rosa (sensível à deficiência), IAC-15 (intermediário) e IAC-Foscarin 31 (tolerante à toxidez) (Mascarenhas et al., 1984, 1990), da espécie Glycine max (L.) Merrill, foram cultivados em solução nutritiva, no período de março a julho de 2006. As médias e respectivos desvios-padrão das temperaturas máxima, mínima e média, durante o período experimental, foram de 33,5 $\pm 0,5,22,1 \pm 0,2$ e $28,6 \pm 0,5{ }^{\circ} \mathrm{C}$.

As sementes foram colocadas para germinar em bandeja rasa com vermiculita, umedecida com solução de sulfato de cálcio $\left(\mathrm{CaSO}_{4}, 0,1 \mathrm{mmol} \mathrm{L}^{-1}\right)$. Quando as plantas atingiram cerca de $5 \mathrm{~cm}$ de altura (estádio fenológico V1), foram transferidas para bandeja plástica com capacidade de $40 \mathrm{~L}$ contendo solução nutritiva (Johnson et al., 1957), adaptada por Epstein \& Bloom (2005), diluída a 1/5 da concentração usual, e com pH de 5,0 (período de adaptação).

Após o terceiro dia do transplante das mudas, quando atingiram o estádio V1 (primeiro par de folhas), foram transplantadas duas plantas por vaso de $2,5 \mathrm{~L}$ (diâmetro de $15 \mathrm{~cm}$ ), com 2,0 L de solução nutritiva. 
Durante o desenvolvimento das plantas, as soluções nutritivas, sob constante aeração, foram renovadas a cada 15 dias, completando-se o volume com água desionizada, quando necessário. As soluções foram preparadas a partir da solução recomendada por Johnson et al. (1957), adaptada por Epstein \& Bloom (2005), e modificadas para fornecer as doses de $\mathrm{Mn}(2$, $100,150,200$ e $\left.250 \mu \mathrm{mol} \mathrm{L}^{-1}\right)$. Na primeira troca de solução nutritiva, as doses corresponderam a $50 \%$ das concentrações nominais.

Colheram-se as plantas no final do ciclo reprodutivo (R7), ocasião em que foram separados caule, folhas inferiores e superiores (limbo e pecíolo), raízes, pericarpos e grãos. O material, devidamente identificado, foi acondicionado em sacos de papel, seco em estufa a $65^{\circ} \mathrm{C}$ durante $72 \mathrm{~h}$ e pesado em balança de precisão. Na ocasião da colheita e separação das plantas, as raízes foram imediatamente lavadas em água corrente, utilizando-se duas peneiras com diâmetro de malha de 0,25 e 1,00 mm. Posteriormente, foram separadas em raiz pivotante e radicelas. A raiz pivotante não foi utilizada nas avaliações dos atributos radiculares (comprimento e superfície total de raízes), embora se constitua em elevada proporção da massa radicular (Araújo et al., 2004).

Para quantificação do comprimento e da superfície radicular de cada unidade experimental, foi retirada uma subamostra, com cerca de $20 \%$ de matéria fresca total (Habib, 1988; Box Jr., 1996), cortando-se vertical e horizontalmente o volume de raízes. Em seguida, para que as partes mais novas e claras das raízes fossem tingidas, essa subamostra foi colocada em copo plástico contendo água e corante (azul de toluidina a $1 \%$ e, então, armazenada na temperatura de $\pm 10^{\circ} \mathrm{C}$, em geladeira (Noordwijk \& Floris, 1979), a fim de se evitar a desidratação e a perda de matéria seca durante a manipulação (separação das raízes em lâminas transparentes $\left.3 \mathrm{M}^{\circledR}, 210 \times 297 \mathrm{~mm}\right)$, devido à respiração. Posteriormente, as imagens das raízes, obtidas com o auxílio de scanner (300 dpi), foram analisadas por meio do aplicativo SIARCS (Sistema Integrado para Análise de Raízes e Cobertura do Solo), versão 3,0. Os valores totais de comprimento e de superfície (área superficial cilíndrica) foram calculados por regra de três direta, relacionando-se os valores da subamostra e de sua matéria seca com a matéria seca total de raízes de cada unidade experimental.

Para estudo da compartimentalização do Mn nas raízes, foi realizado outro experimento: duas plantas, após o período de adaptação em bandeja de germinação, foram transplantadas para vasos de 2,5 L (diâmetro de $15 \mathrm{~cm}$ ), com 2,0 L de solução nutritiva, contendo Mn nas concentrações de 2 e $250 \mu \mathrm{mol} \mathrm{L}^{-1}$, onde permaneceram por $48 \mathrm{~h}$. Após esse período, as plantas foram removidas da solução nutritiva e separadas em raízes e parte aérea. Após o corte das plantas, efetuouse a determinação do Mn trocável e não-trocável, conforme métodos descritos por Munns et al. (1963) e Wang (2003). Para isso, foram coletadas duas amostras das raízes, por tratamento, as quais foram previamente lavadas com água desionizada. Em seguida, adicionou-se uma porção da amostra de raiz em um recipiente com solução de "dessorção" $\left(2 \mathrm{mmol} \mathrm{L}^{-1}\right.$ de $\mathrm{CuCl}_{2}, 0,5 \mathrm{mmol} \mathrm{L}^{-1}$ de $\mathrm{CaCl}_{2}$ e $100 \mathrm{mmol} \mathrm{L}^{-1} \mathrm{de} \mathrm{HCl}$ ), sendo o conjunto raiz + solução mantido a $\pm 5^{\circ} \mathrm{C}$, em geladeira, por cerca de $30 \mathrm{~min}$. Após o processo de dessorção, as raízes foram lavadas em água desionizada, secas $\left(65^{\circ} \mathrm{C}\right.$ durante $72 \mathrm{~h}$ ) e pesadas e efetuou-se a quantificação do Mn. Utilizouse o $\mathrm{CaCl}_{2}\left(0,5 \mathrm{mmol} \mathrm{L}^{-1}\right)$ para manter a integridade da parede celular durante a dessorção do $\mathrm{Mn}$, e o $\mathrm{Cu}$ $\left(\mathrm{CuCl}_{2}, 2 \mathrm{mmol} \mathrm{L}^{-1}\right)$, por se ligar fortemente à parede celular, liberando o $\mathrm{Mn}^{2+}$ ligado aos sítios de troca do apoplasto radicular (Wang, 2003).

Em ambas as amostras de raízes, imersas na solução de dessorção e não-imersas, a determinação da concentração de $\mathrm{Mn}$ foi efetuada por espectrometria de absorção atômica, conforme método descrito por Malavolta et al. (1997). O total de Mn absorvido foi determinado na amostra de raiz que não foi colocada na solução de dessorção. A absorção "simplástica" de Mn foi atribuída à determinação do Mn remanescente nas raízes imersas na solução de dessorção. Portanto, o Mn total absorvido refere-se ao Mn alocado no simplasto e apoplasto, e a diferença entre o total de Mn absorvido e o Mn absorvido no simplasto representa a fração do Mn retido no apoplasto (Munns et al., 1963; Wang, 2003).

O delineamento experimental utilizado no primeiro experimento foi o de blocos completos ao acaso, com os tratamentos arranjados em esquema fatorial $5 \times 3$ (cinco doses de Mn x três cultivares de soja), com três repetições. No segundo experimento, o delineamento foi o de blocos completos ao acaso, com os tratamentos arranjados em esquema fatorial 2 × 3 (duas doses de Mn x três cultivares de soja), com quatro repetições. Submeteram-se os resultados às análises estatísticas, utilizando-se o programa estatístico SAS - System for Windows 6.11 (SAS, 1996). Realizou-se a análise de variância e, de acordo com o nível de significância no teste $\mathrm{F}$ para as doses de $\mathrm{Mn}$, procedeu-se ao estudo de regressão de primeiro e segundo graus, pelo procedimento GLM. No experimento para avaliação da compartimentalização do Mn nas raízes, as médias dos resultados obtidos foram comparadas pelo teste de Tukey a $5 \%$.

\section{RESULTADOS E DISCUSSÃO}

A primeira manifestação da toxidez de Mn ocorreu nas folhas novas do cultivar IAC-15, mantidas em solução com a concentração de $200 \mu \mathrm{mol} \mathrm{L}^{-1}$ de $\mathrm{Mn}$, oito dias após início dos tratamentos. A seguir, aos nove dias, também na mesma dose, houve sintomas 
de toxidez nas folhas novas do cultivar Santa Rosa (Figura 1). Os sintomas, em ambos os cultivares, foram caracterizados por aparecimento de pontuações necróticas entre as nervuras das folhas novas, clorose foliar, aspecto de murcha, tamanho reduzido e má formação dos limbos foliares (retorcimento do limbo e das nervuras), com o avanço da toxicidade - sintomas que estão de acordo com os relatos da literatura. Para o cultivar IAC-Foscarin 31, não foram constatadas anomalias visuais associadas à toxidez de Mn durante todo o ciclo da planta, o que indica tolerância ao excesso de Mn.

Os valores médios das concentrações de Mn nessas folhas do IAC-15, Santa Rosa e IAC-Foscarin 31, no final do experimento, foram de 1.003, 850 e $843 \mathrm{mg} \mathrm{kg}^{-1}$, respectivamente, para a dose de $\mathrm{Mn}$ de $250 \mathrm{\mu mol} \mathrm{L}^{-1}$. Esses valores estão próximos daqueles relatados por Fageria (2001), o qual atribuiu concentrações no tecido vegetal de 67 e $720 \mathrm{mg} \mathrm{kg}^{-1}$, como teores adequado e tóxico, respectivamente, para plantas de soja. Lima et al. (2004) relataram concentrações de Mn de até $1.800 \mathrm{mg} \mathrm{kg}^{-1}$ na parte aérea de plantas de soja (Emgopa 316) cultivadas em solos com altos teores do elemento. Portanto, podem-se associar essas variações, entre os valores relatados e os do presente estudo, a diferenças genotípicas quanto a absorção, transporte ou distribuição do $\mathrm{Mn}$.

$\mathrm{Na}$ avaliação das concentrações de $\mathrm{Mn}$ nos tecidos, considerando as doses de Mn na solução nutritiva, observou-se comportamento diferenciado entre os cultivares (Figura 2). No IAC-15, com o aumento da concentração de Mn na solução nutritiva de 100 para $250 \mu \mathrm{mol} \mathrm{L}^{-1}$, foram constatados incrementos nos teores de Mn nos grãos (exceto na dose mais elevada), nos pericarpos e nas folhas superiores e inferiores, as quais apresentaram sintomas visuais de toxidez mais acentuados. Por outro lado, o IAC-Foscarin 31, que não manifestou sintoma visual de toxidez, de modo geral, exibiu menor teor de Mn nos grãos, pericarpos, folhas e caules. Pode-se observar, entretanto, maior teor de Mn nas raízes. Dessa forma, o IAC-Foscarin 31 parece ter um mecanismo de regulação que limita o transporte para a parte aérea quando o nutriente se encontra em concentrações excessivas ou tóxicas. Tsukamoto et al. (2006) também constataram baixa redistribuição do ${ }^{52} \mathrm{Mn}$ das raízes para as folhas de cevada quando as plantas foram mantidas em condição de excesso do nutriente no substrato.

Com o aumento da concentração de Mn na solução nutritiva, houve incremento no acúmulo do nutriente na parte aérea dos cultivares. Entretanto, esse acúmulo foi mais acentuado no IAC-15. Na maior dose de Mn na solução nutritiva, as raízes do cultivar IAC-Foscarin 31 acumularam 2,70 mg/vaso, enquanto para IAC-15 e Santa Rosa foram de 2,33 e $2,02 \mathrm{mg} / \mathrm{vaso}$, respectivamente. Na mesma condição e para a parte aérea, as quantidades foram de 21,43 e $14 \mathrm{mg} /$ vaso, respectivamente, para IACFoscarin 31, IAC-15 e Santa Rosa e corresponderam a 89,95 e 87 \% do total absorvido pelas plantas. Do total acumulado na parte aérea (transporte a longa distância) do IAC-Foscarin 31, cerca de 13,5 \% do Mn distribuiu-se nos grãos e nos pericarpos, enquanto para o IAC-15 e Santa Rosa esses valores corresponderam, respectivamente, a 23 e $11 \%$.

Edwards \& Asher (1982) observaram que há dois mecanismos de tolerância ao Mn em plantas de soja. No primeiro, a planta absorve bastante $\mathrm{Mn}$ sem prejuízos ao crescimento, o que é atribuído à tolerância interna ao elemento. No segundo, a planta controla a absorção radicular, não permitindo o transporte a longa distância. No presente estudo, o cultivar IACFoscarin 31 foi bastante tolerante, sugerindo que $o$ segundo mecanismo de tolerância esteja envolvido, o que pôde ser confirmado pela maior concentração do metal no apoplasto radicular, quando comparado com os demais cultivares (Quadro 1).

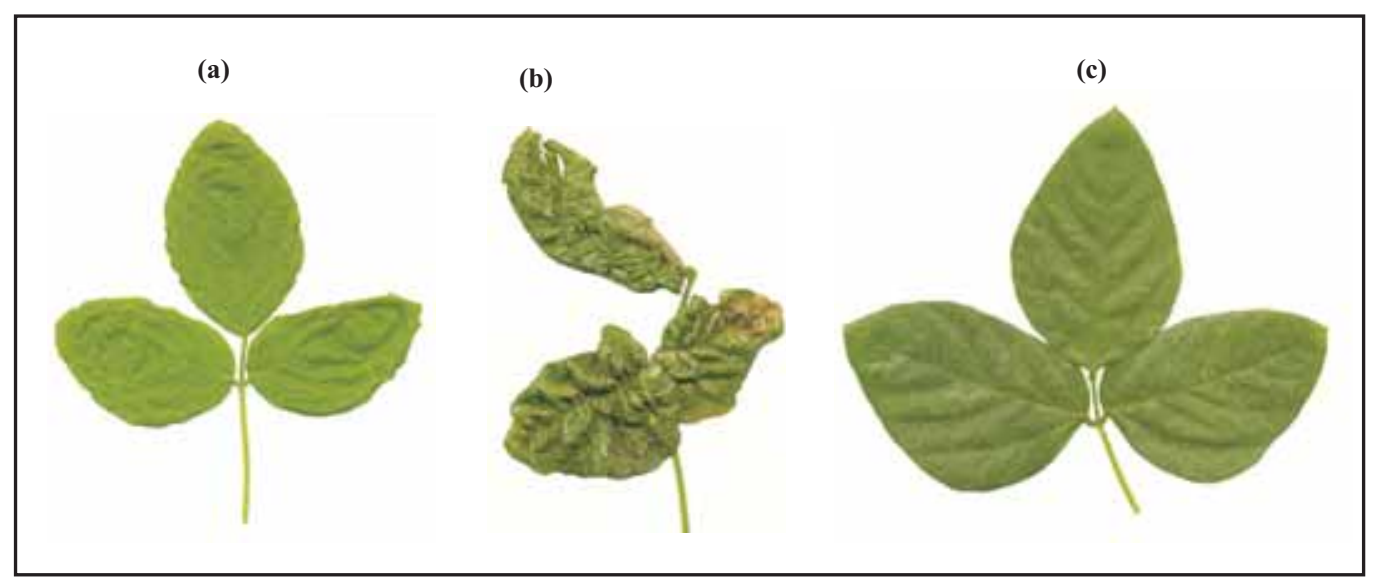

Figura 1. Sintomas de toxidez de Mn manifestada pelo cultivar IAC-15, a partir do oitavo dia após início do tratamento, considerando as doses de $\mathrm{Mn}$ de $200 \mu \mathrm{mol} \mathrm{L} \mathrm{L}^{-1}$ (a), de $250 \mu \mathrm{mol} \mathrm{L}{ }^{-1}$ (b), em fase mais avançada, e de $2,0 \mu \mathrm{mol} \mathrm{L} \mathrm{L}^{-1}$ (c), com trifólio sadio, sem sintoma. 
Para superfície total de raízes, verificou-se, por meio das equações polinomiais de regressão, que as concentrações de Mn de 268, 204 e $437 \mu \mathrm{mol} \mathrm{L}{ }^{-1}$ promoveriam valores mínimos de superfícies radiculares para os cultivares Santa Rosa, IAC-15 e IACFoscarin 31, respectivamente (Figura 3a). Esse fato realça a maior tolerância do IAC-Foscarin 31 ao excesso de Mn na solução nutritiva.

O comprimento total de raízes, com o aumento das doses de Mn, mostrou comportamento semelhante ao da superfície radicular. As doses de Mn correspondentes aos menores comprimentos foram de 266, $201 \mathrm{e}$ $424 \mu \mathrm{mol} \mathrm{L}^{-1}$, respectivamente, para os cultivares Santa Rosa, IAC-15 e IAC-Foscarin 31 (Figura 3b). Com o aumento do suprimento de Mn na solução, da dose mais baixa para a mais alta, nos cultivares Santa Rosa, IAC-15 e IAC-Foscarin 31, constatou-se redução no comprimento total de raízes, respectivamente, de 81,69 e $64 \%$.

A arquitetura de raiz é importante por determinar a exploração do solo e, portanto, a aquisição de água e de nutrientes. A geometria radicular, sob controle
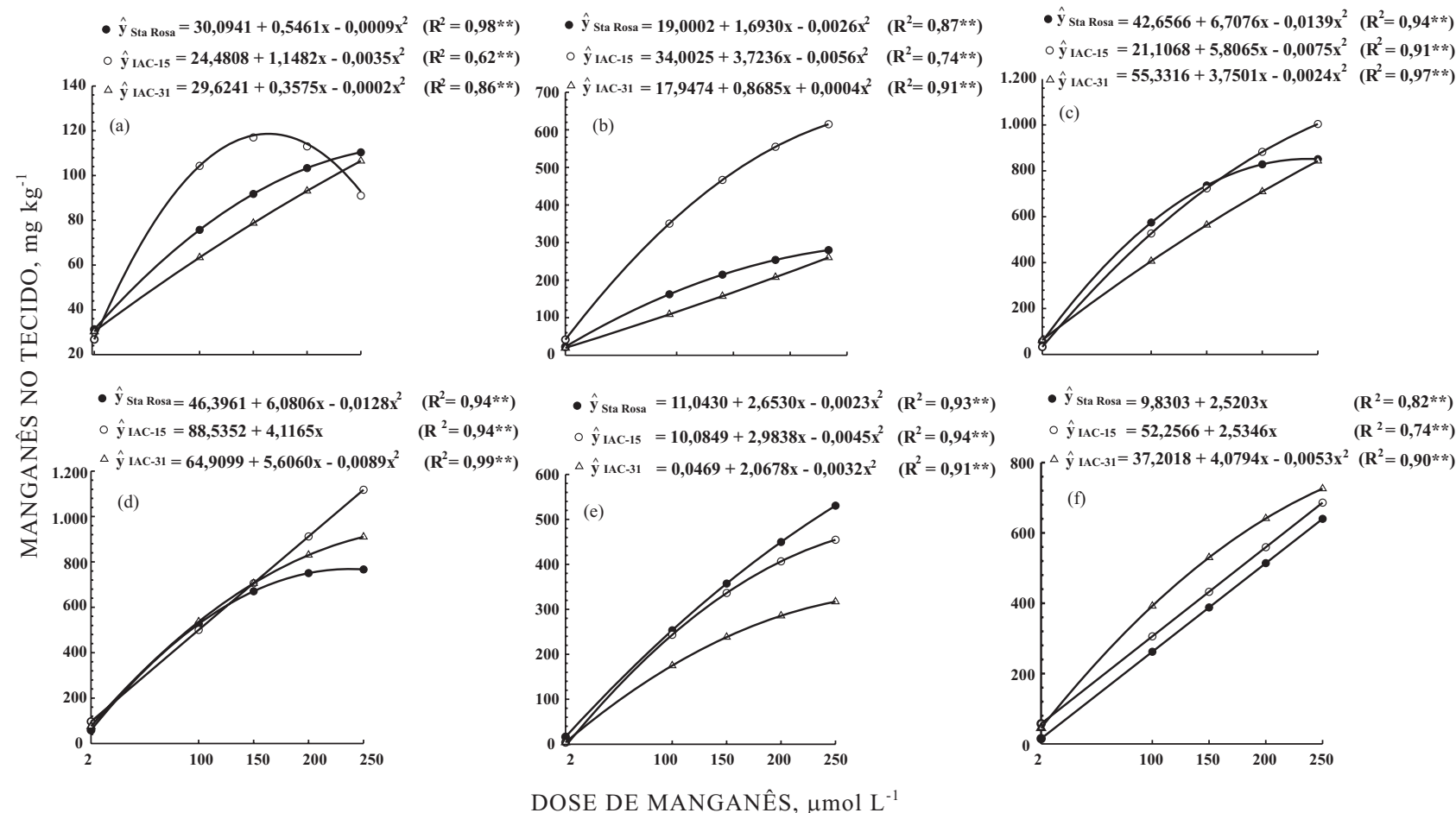
$200 \Delta \hat{y}{ }_{1 A C-31}=55,3316+3,7501 x-0,0024 x^{2} \quad\left(R^{2}=0,97 * *\right)$

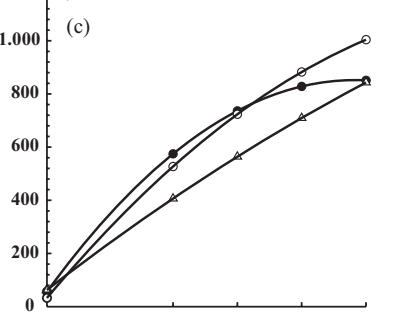

- $\hat{\mathbf{y}}_{\text {Sta Rosa }}=\mathbf{9 , 8 3 0 3}+\mathbf{2 , 5 2 0 3 \mathrm { x }} \quad\left(\mathrm{R}^{2}=\mathbf{0 , 8 2 * *}\right)$ $\circ \hat{y}_{\text {IAC-15 }}=\mathbf{5 2 , 2 5 6 6 + 2 , 5 3 4 6 x} \quad\left(R^{2}=0,74 * *\right)$ ${ }^{800} \mathrm{C}^{\triangle} \hat{\mathrm{y}} \mathrm{IAC}-31_{1}=37,2018+4,0794 \mathrm{x}-0,0053 \mathrm{x}^{2} \quad\left(R^{2}=0,90 * *\right)$

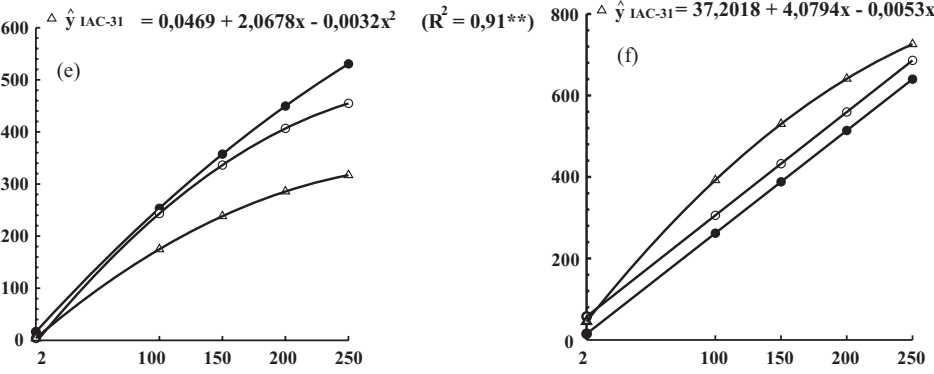

DOSE DE MANGANÊS, $\mu \mathrm{mol} \mathrm{L} \mathrm{L}^{-1}$

Figura 2. Concentração de Mn nos grãos (a), nos pericarpos (b), nas folhas superiores (c), nas folhas inferiores (d), nos caules (e) e nas raízes (f) dos cultivares Santa Rosa (๑), IAC-15 (o) e IAC-Foscarin 31 ( $\Delta$ ), considerando as doses de $2,100,150,200$ e $250 \mu \mathrm{mol} \mathrm{L}^{-1}$ de $\mathrm{Mn}$, em solução nutritiva.
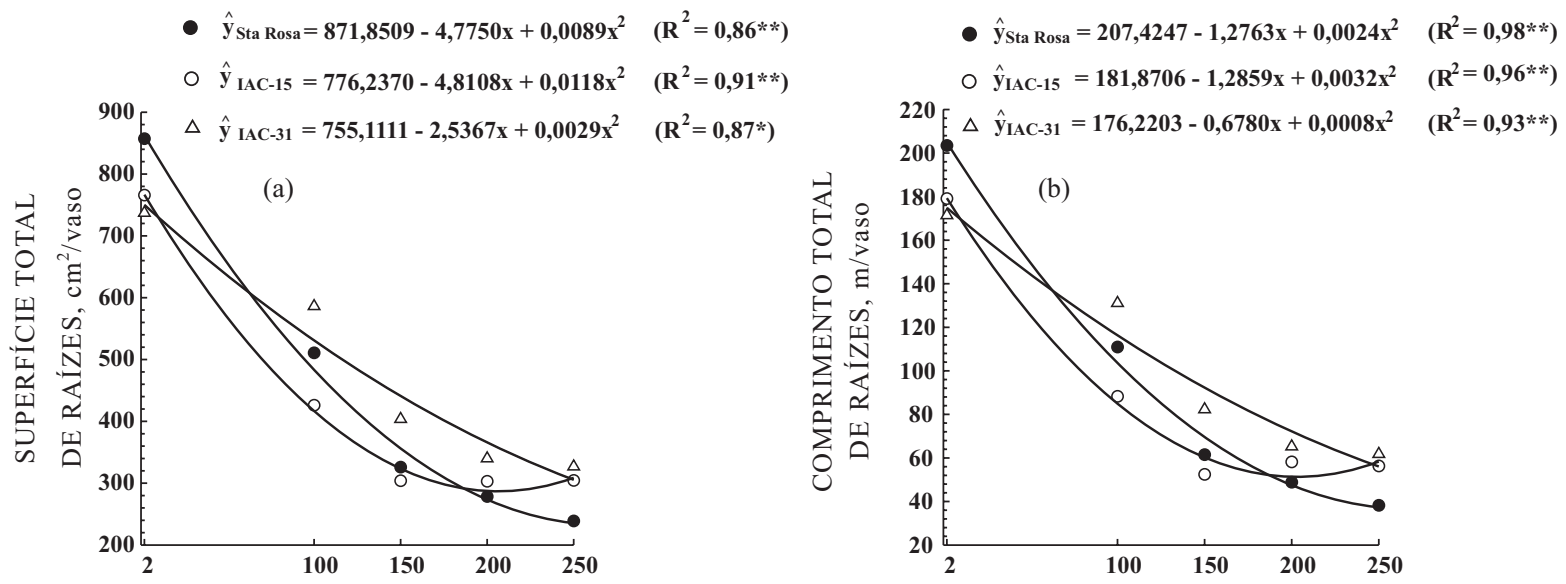

DOSE DE MANGANÊS, $\mu \mathrm{mol} \mathrm{L} \mathrm{L}^{-1}$

Figura 3. Superfície total (a) e comprimento total de raízes (b) dos cultivares Santa Rosa (o), IAC-15 (o) e IAC-Foscarin $31(\Delta)$, considerando as doses de 2, 100, 150, 200 e $250 \mu \mathrm{mol} \mathrm{L} \mathrm{L}^{-1} \mathrm{de} \mathrm{Mn,} \mathrm{em} \mathrm{solução} \mathrm{nutritiva.}$ 
Quadro 1. Absorção radicular total, no simplasto e no apoplasto de Mn pelos cultivares de soja Santa Rosa, IAC-15 e IAC-Foscarin 31, expostos em duas concentrações de Mn na solução nutritiva, após 48 h

\begin{tabular}{|c|c|c|c|c|c|c|c|c|c|}
\hline \multirow{2}{*}{$\begin{array}{c}\text { Dose } \\
\text { Mn em solução }\end{array}$} & \multicolumn{3}{|c|}{ Mn total } & \multicolumn{3}{|c|}{ Mn simplasto } & \multicolumn{3}{|c|}{ Mn apoplasto } \\
\hline & Sta. Rosa & IAC-15 & IAC-31 & Sta. Rosa & IAC-15 & IAC-31 & Sta. Rosa & IAC-15 & IAC-31 \\
\hline$\mu \mathrm{mol} \mathrm{L}{ }^{-1}$ & & & & & $\mathrm{mg} \mathrm{kg}^{-1}$ & & & & \\
\hline 2,0 & $36,5 \mathrm{bC}$ & $77,6 \mathrm{aA}$ & $68,2 \mathrm{bB}$ & $28,9 \mathrm{bB}$ & $61,9 \mathrm{bA}$ & $60,3 \mathrm{bA}$ & $7,6 \mathrm{bB}$ & 15,7 aA & $7,9 \mathrm{bB}$ \\
\hline 250,0 & 91,3 aB & $67,3 \mathrm{bB}$ & 134,8 aA & $58,5 \mathrm{aB}$ & $66,2 \mathrm{aB}$ & $83,5 \mathrm{aA}$ & 32,8 aA & $1,1 \mathrm{bB}$ & 51,3 aA \\
\hline CV (\%) & 1,02 & 0,70 & 15,59 & 2,26 & 1,46 & 5,34 & 7,70 & 5,47 & 41,63 \\
\hline DMS & 1,99 & 1,74 & 55,58 & 3,48 & 3,29 & 13,50 & 5,46 & 1,62 & 43,24 \\
\hline
\end{tabular}

Médias seguidas por letras distintas, minúscula entre as doses e maiúscula entre os cultivares, diferem entre si pelo teste de Tukey a $5 \%$.

genético, caracteriza-se, entre outras características, pela formação de raízes adventícias e laterais. A variação genética no comprimento e na densidade radicular exerce influência tanto na aquisição de nutrientes, como o P, K, Ca e Mg, quanto na tolerância ao excesso de $\mathrm{Al}$ e Mn, em solos ácidos (Lynch, 2007).

As raízes dos cultivares IAC-15 e IAC-Foscarin 31, a partir da dose de Mn de $100 \mu \mathrm{mol} \mathrm{L-1}$, apresentaram coloração escura, enquanto aquelas do Santa Rosa eram claras, muito finas e a raiz pivotante não era bem definida. Alam et al. (2001) relataram que as plantas de cevada cultivadas em solução nutritiva, com excesso de $\mathrm{Mn}$, apresentavam raízes com coloração escura (marrom), atribuindo o escurecimento a uma possível deposição de óxido de $\mathrm{Mn}$ e de compostos fenólicos. Rout et al. (2001) observaram que os genótipos de feijão-mungo e de arroz, tolerantes ao excesso de Mn na solução nutritiva, exibiram raízes mais desenvolvidas, quando comparadas às plantas menos tolerantes. Estes autores também constataram maior acúmulo de Mn nas raízes dos genótipos tolerantes, concluindo que a ligação do metal às matrizes pécticas das paredes celulares, o "carregamento" do metal para os vacúolos, em virtude da ativação de adenosina trifosfatases (ATP-ases) nas membranas, a complexação com ácidos orgânicos e uma possível ligação com proteínas específicas, bem como alterações nas estruturas das membranas, podem constituir estratégias eficientes para tolerância ao excesso de Mn.

A afinidade de transportadores, localizados nas membranas dos vacúolos, aos elementos como Fe, Mn e $\mathrm{Zn}$, bem como o papel destes transportadores na manutenção do metabolismo no citossol, têm sido discutidos recentemente, visando elucidar os mecanismos de tolerância ao excesso em plantas hiperacumuladoras e também a eficiência de uso em espécies cultivadas (Korshunova et al., 1999; Reid \& Hayes, 2003; Eguez et al., 2004; Martinoia et al., 2007). Além disso, pode ser possível que, a exemplo do que acontece com outros metais pesados, haja desintoxicação celular do excesso de Mn por fitoquelatinas, como relatado por Bidwell et al. (2002), em Austromyrtus bidwillii, espécie florestal hiperacumuladora de Mn.

Com relação às acumulações de Mn no simplasto, apoplasto e a total (Quadro 1), constata-se que, comparando os cultivares na dose de $2 \mu \mathrm{mol} \mathrm{L}-1$, o IAC15 apresentou o maior acúmulo total, com significativa contribuição do simplasto. A fração adsorvida de Mn no apoplasto do IAC- 15 foi significativamente maior do que a do Santa Rosa e a do IAC-Foscarin 31, os quais não diferiram entre si. Com a elevação da concentração de Mn na solução nutritiva, o acúmulo total de Mn no IAC-Foscarin 31 aumentou em 98 \%, enquanto no cultivar Santa Rosa o incremento foi de $150 \%$. Diferentemente, no IAC-15 ocorreu redução no acúmulo de Mn total e no apoplasto, embora com significativo acúmulo no simplasto. Pode-se inferir, portanto, que o acúmulo no simplasto represente uma das causas da manifestação inicial dos sintomas de toxidez. Na maior dose de $\mathrm{Mn}$, observou-se que o acúmulo de Mn no simplasto, em relação ao total, foi aproximadamente de $63 \%$ nos cultivares IACFoscarin 31 e Santa Rosa e em torno de 98 \% no IAC15. Assim, a maior participação do Mn no apoplasto do IAC-Foscarin 31 representaria mecanismo significativo para tolerância ao excesso.

A tolerância ao excesso de Mn, assim como de outros metais pesados, em diversas espécies vegetais, tem sido atribuída ao poder de retenção do excesso nas raízes. Essa capacidade depende, em parte, da formação de complexos no sistema radicular (Yang et al., 1997; Han et al., 2006). Por sua vez, esses complexos podem apresentar diferenças quanto à sua mobilidade das raízes para a parte aérea. Metais com elevada eletronegatividade, como o $\mathrm{Cu}$ e Co, formam complexos estáveis nas raízes e são aí acumulados. Por sua vez, elementos com baixa eletronegatividade, como o Mn e Zn, são facilmente transportados a longa distância (Horiguchi, 1987). Wang (2003), estudando a 
absorção de Mn e a compartimentalização do nutriente em raízes de plantas de fumo, constatou que, para o genótipo sensível ao excesso de Mn em solução, o padrão de absorção radicular foi o mesmo ao longo de todo o período experimental, ao passo que, para o genótipo tolerante, houve decréscimo do Mn absorvido pelas raízes logo após 180 min de exposição à solução com Mn em excesso. Essa redução na absorção radicular foi associada à exclusão do Mn localizado no apoplasto, apesar da contínua absorção via simplasto, podendo-se concluir que a diferença de absorção radicular apresentada pelos genótipos foi causada pelo apoplasto.

De modo geral, o cultivar IAC-15 apresentou, em todas as doses de $\mathrm{Mn}$, as maiores produções de matéria seca, quando comparado aos demais cultivares, exceto para matéria seca de raízes, para a qual o IACFoscarin 31 foi superior (Figura 4). Com o aumento da concentração de Mn na solução nutritiva, constatouse redução na produção de matéria seca do sistema radicular dos cultivares Santa Rosa, IAC-15 e IACFoscarin 31, respectivamente, de 65, 54 e $50 \%$, resultado que reforça a maior tolerância do IACFoscarin 31 ao excesso de Mn.

Na dose mais alta de Mn, constatou-se diferença na produção de grãos do cultivar IAC-15 superior em
64 e $54 \%$, respectivamente, ao Santa Rosa e IACFoscarin 31. O mesmo comportamento foi observado para produção de matéria seca de pericarpos, da parte aérea e total. Esse comportamento pode ser explicado por característica do próprio genótipo ou pela época tardia de plantio, que no presente experimento de casa de vegetação foi em março (final do verão), favorecendo os cultivares de ciclo médio ou tardio (Marchiori et al., 1999; Crusciol et al., 2002), no caso, o IAC-15. Por outro lado, o cultivar IAC-Foscarin 31 apresentou maior produção de matéria seca de raízes em todas as doses de Mn fornecidas na solução, exceto na dose de $2 \mu \mathrm{mol} \mathrm{L}-1$ (Figura 4). Em todos os genótipos, a partir da dose de Mn de $100 \mu \mathrm{mol} \mathrm{L}^{-1}$, ocorreu redução na contribuição de matéria seca da raiz pivotante para a matéria seca total de raízes. Nessa condição, todas as raízes eram finas e frágeis e não foram diferenciadas.

Quanto à produção de matéria seca da parte aérea, com aumento da concentração de $\mathrm{Mn}$, houve reduções de 41,40 e $51 \%$, o que promoveu efeito diferenciado na relação de matéria seca da parte aérea:raiz entre os genótipos (Figura 3f). Verifica-se, portanto, maior equilíbrio funcional entre a relação parte aérea:raiz no IAC-Foscarin 31, em todas as doses de Mn empregadas no estudo, o que pode indicar outra estratégia de adaptação ao excesso do Mn no substrato.
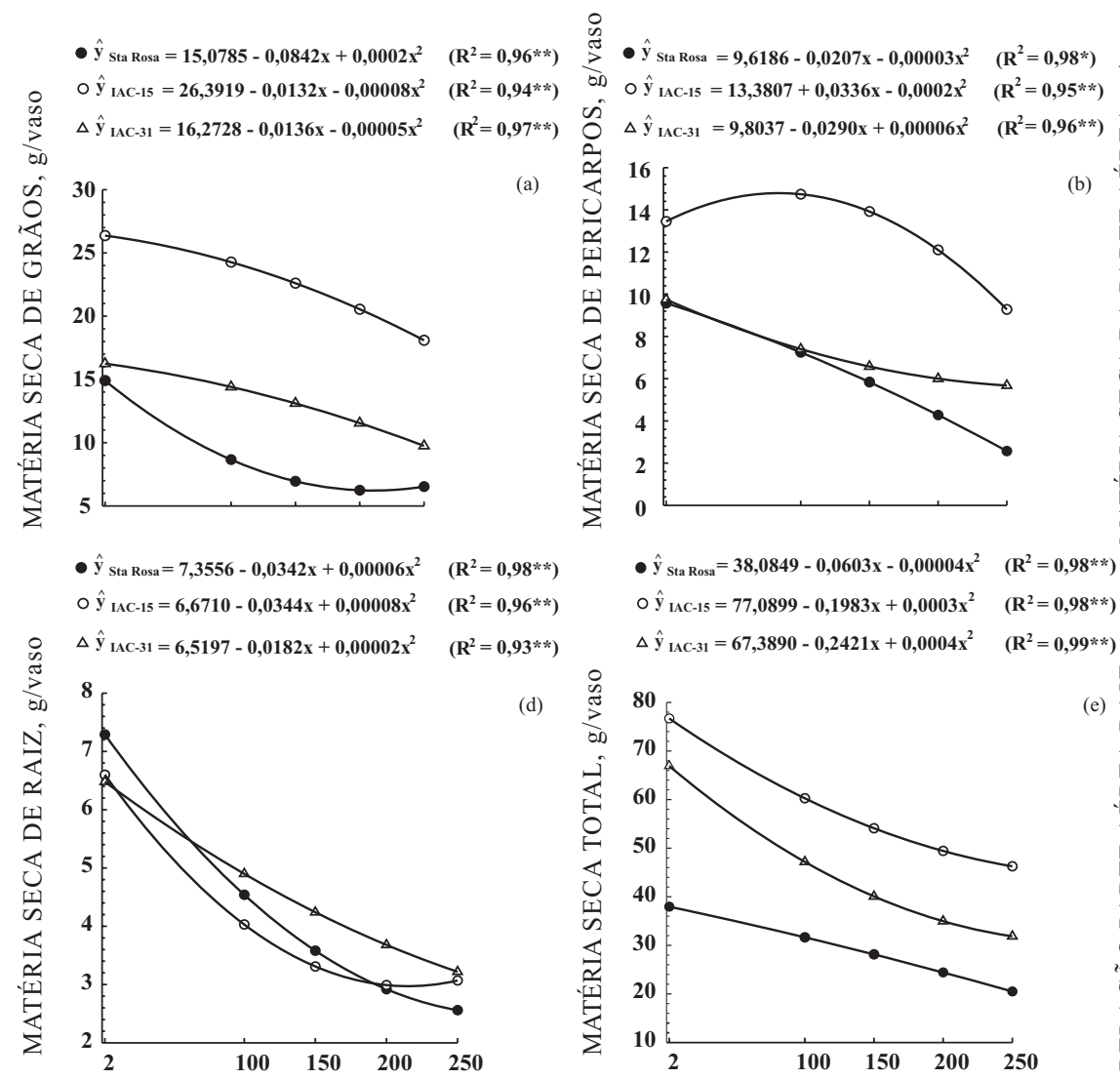

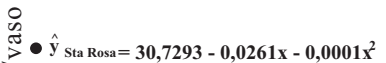

$\left(\mathrm{R}^{2}=0,96^{*}\right)$ $\circ \hat{y}_{\text {IAC-15 }}=70,4189-0,1639 x+0,0002 x^{2} \quad\left(R^{2}=0,97^{* *}\right)$

$\Delta \hat{\mathbf{y}}_{\text {IAC-31 }}=60,8693-0,2240 \mathrm{x}+0,0004 \mathrm{x}^{2} \quad\left(\mathrm{R}^{2}=0,99^{* * *}\right)$

of $\circ \hat{y}_{\text {IAC-15 }}=13,3807+0,0336 x-0,0002 x^{2} \quad\left(R^{2}=0,95^{* *}\right)$

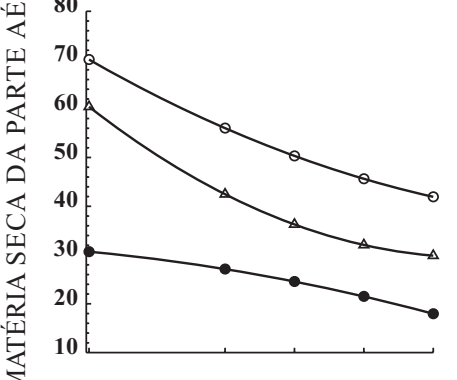

(c)

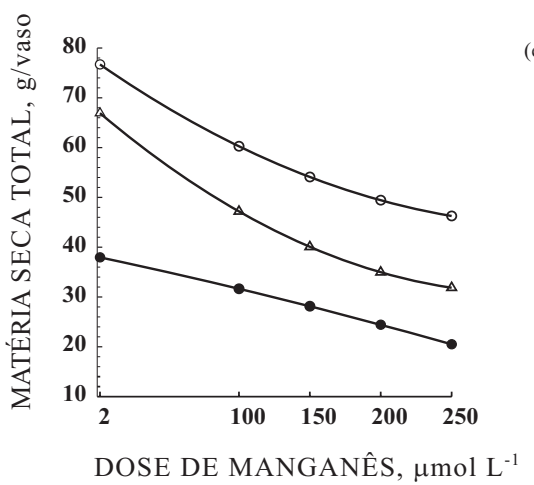

- $\hat{\mathbf{y}}_{\text {Sta Rosa }}=4,034+0,0307 \mathrm{x}-0,00008 \mathrm{x}^{2} \quad\left(\mathrm{R}^{2}=0,98^{* *}\right)$

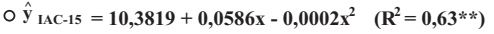

$\Delta \hat{\mathbf{y}}_{\text {IAC-31 }}=9,2804-0,0072 \mathrm{x}-0,00001 \mathrm{x}^{2} \quad\left(\mathrm{R}^{2}=0,16^{\mathrm{ns}}\right)$

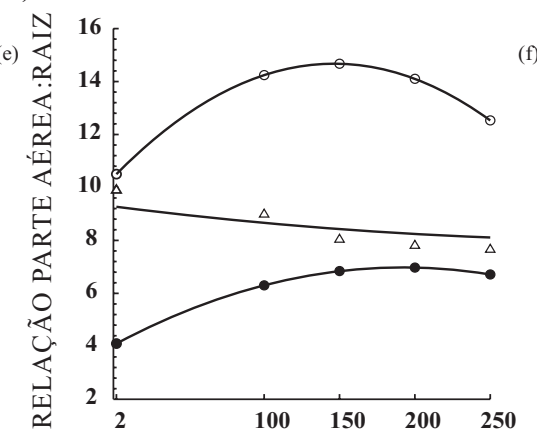

(f)

Figura 4. Produção de matéria seca (a) de grãos, (b) de pericarpos, (c) de matéria seca da parte aérea, (d) de raízes, (e) de matéria seca total e (f) relação parte aérea:raiz dos cultivares Santa Rosa (৫), IAC-15 (o) e IAC-Foscarin $31(\Delta)$, considerando as doses de 2, 100, 150, 200 e $250 \mu \mathrm{mol} \mathrm{L} \mathrm{L}^{-1}$ de $\mathrm{Mn}$, em solução nutritiva. 


\section{CONCLUSÕES}

1. No IAC-Foscarin 31, o maior acúmulo de Mn e a compartimentalização no apoplasto das raízes reduzem o transporte deste nutriente a longa distância e são fenômenos determinantes na tolerância ao excesso de Mn em solução.

2. Os maiores comprimento e superfície total de raízes e as maiores produções de matéria seca total e do sistema radicular do IAC-Foscarin 31 foram estratégias responsáveis pela maior tolerância e adaptação ao excesso do $\mathrm{Mn}$.

\section{AGRADECIMENTOS}

Ao Drs. Hipólito Assunção Antonio Mascarenhas e Roberto Tetsuo Tanaka, do Instituto Agronômico de Campinas, e aos Drs. Leones Alves de Almeida e Fábio Álvares de Oliveira, da Embrapa Soja, pelo fornecimento das sementes de soja.

À CAPES e à FAPESP (Ref. Proc. 04/09411-4), pelo apoio financeiro e institucional à realização deste trabalho. Ao CNPq, pela bolsa de Produtividade (303184/2006-0) em Pesquisa concedida a Eurípedes Malavolta e de Pós-Doutorado Júnior (150502/2007-9) concedida a José Lavres Júnior. À FAPESP (Ref. Proc. 04/15897-7), pela bolsa de doutorado concedida a Milton Ferreira de Moraes.

\section{HOMENAGEM}

À memória do Mestre e Amigo, Professor Malavolta, falecido em 19/1/2008. Seus exemplos de perseverança, dedicação ao trabalho e conduta como cientista e Homem continuarão a inspirar aqueles que tiveram o privilégio da convivência.

\section{LITERATURA CITADA}

ADRIANO, D.C. Trace elements in terrestrial environments Biogeochemistry, bioavailability, and risks of metals. 2.ed. New York, Springer-Verlag, 2001. 867p.

ALAM, S.; KAMEI, S. \& KAWAI, S. Amelioration of manganese toxicity in barley with iron. J. Plant. Nutr., 24:1421-1433, 2001

ARAÚJO, A.P.; FERNANDES, A.M.; KUBOTA, F.Y.; BRASIL, F.C. \& TEIXEIRA, M.G. Sample size for measurement of root traits on common bean by image analysis. Pesq. Agropec. Bras., 39:313-318, 2004.

BIDWELL, S.D.; WOODROW, I.E.; BATIANOFF, G.N. \& SOMMER-KNUDSEN, J. Hyperaccumulation of manganese in the rainforest tree Austromystus bidwillii (Myrtaceae) from Queensland, Australia. Funct. Plant Biol., 29:899-905, 2002.
BOX JR., J.E. Modern methods for root investigations. In: WAISEL, Y.; ESHEL, A. \& KAFKAFI, U., eds. Plant roots: The ridden half. 2.ed. New York, Marcel Dekker, 1996. p.193-237.

CLUNE, S.T. \& COPELAND, L. Effects of aluminum on canola roots. Plant Soil, 216:27-33, 1999.

CRUSCIOL, C.A.C.; LAZARINI, E.; BUZO, C.L. \& SÁ, M.E. Produção e qualidade fisiológica de sementes de soja avaliadas na semeadura de inverno. Sci. Agric., 59:79-86, 2002 .

EDWARDS, D.G. \& ASHER, C.J. Tolerance of crop and pasture species to manganese toxicity. In: INTERNATIONAL PLANT NUTRITION COLLOQUIUM, 9., Warwick, 1982. Proceedings. Farnham Royal, Commonwealth Agricultural Bureau, 1982. p.145-150.

EGUEZ, L.; CHUNG, Y.S.; KUCHIBHATLA, A.; PAIDHUNGAT, M. \& GARRET, S. Yeast $\mathrm{Mn}^{2+}$ transporter, Smf1p, is regulated by ubiqutin-dependent vacuolar protein sorting. Genetics, 167:107-117, 2004.

EPSTEIN, E. \& BLOOM, A.J. Mineral nutrition of plants: Principles and perspectives. 2.ed. Sunderland, Sinauer, 2005. 400p.

FAGERIA, N.K. Adequate and toxic levels of copper and manganese in upland rice, common bean, corn, soybean and wheat grown on an Oxisol. Comm. Soil Sci. Plant Anal., 32:1659-1676, 2001.

FOY, C.D.; SCOTT, B.J. \& FISHER, J.A. Genetics and breeding of plant of manganese toxicity. In: GRAHAM, R.D.; HANNAM, R.J. \& UREN, N.C., eds. Manganese in soils and plants. Dordrecht, Kluwer Academic Publishers, 1988. p.293-307.

HABIB, R. Total root length as estimated from small subsamples. Plant Soil, 108:267-274, 1988.

HAN, F.; SHAN, X.; ZHANG, S.; WEN, B. \& OWENS, G. Enhanced cadmium accumulation in maize roots - The impact of organic acids. Plant Soil, 289:355-368, 2006.

HORIGUCHI, T. Mechanism of manganese toxicity and tolerance of plants. II. Deposition of oxidized manganese in plant tissues. Soil Sci. Plant Nutr., 33:595-606, 1987.

JOHNSON, C.M.; STOUT, P.R.; BROYER, T.C. \& CARLTON, A.B. Comparative chlorine requirements of different plants species. Plant Soil, 8:337-353, 1957.

KABATA-PENDIAS, A. \& PENDIAS, H. Trace elements in soils and plants. 3.ed. Boca Raton, CRC Press, 2001. 413p.

KORSHUNOVA, Y.O.; EIDE, D.; CLARK, W.G.; GUERINOT, M.L. \& PAKRASI, H.B. The IRT1 protein from Arabidopsis thaliana is a metal transporter with a broad substrate range. Plant Molec. Biol., 40:37-44, 1999.

LIMA, D.V.; KLIEMANN, H.J.; MORAES, M.F. \& LEANDRO, W.M. Relações entre doses de calcário e manganês na nutrição mineral da soja na região de Rio Verde - GO. Pesq. Agropec. Trop., 34:61-69, 2004.

LYNCH, J.P. Roots of the second green revolution. Austr. J. Bot., 55:493-512, 2007. 
MALAVOLTA, E. \& KLIEMANN, H.J. Desordens nutricionais no Cerrado. Piracicaba, Potafos, 1985. 136p.

MALAVOLTA, E.; VITTI, G.C. \& OLIVEIRA, S.A. Avaliação do estado nutricional das plantas: Princípios e aplicações. 2.ed. Piracicaba, Potafos, 1997. 319p.

MARCHIORI, L.F.S.; CÂMARA, G.M.S.; PEIXOTO, C.P. \& MARTINS, M.C. Desempenho vegetativo de cultivares de soja [Glycine max (L.) Merrill] em épocas normal e safrinha. Sci. Agric., 56:383-390, 1999.

MARTINOIA, E.; MAESHIMA, M. \& NEUHAUS, H.E. Vacuolar transporters and their essential role in plant metabolism. J. Exp. Bot., 58:83-102, 2007.

MASCARENHAS, H.A.A.; CAMARGO, C.E.O. \& FALIVENE, S.M.P. Comportamento de cultivares de soja em solução nutritiva contendo diferentes níveis de manganês. Bragantia, 43:201-209, 1984.

MASCARENHAS, H.A.A.; MIRANDA, M.A.C.; TANAKA, R.T.; FALIVENE, S.M.P. \& DECHEN, A.R. Comportamento de cultivares precoces de soja em solução nutritiva contendo diferentes níveis de manganês. Pesq. Agropec. Bras., 25:609-615, 1990.

MIYASAKA, S.C.; KOCHIAN, L.V.; SHAFF, J.E. \& FOY, C.D. Mechanisms of $\mathrm{Al}$ tolerance in wheat - An investigation of genotypic differences in rhizosphere $\mathrm{pH}, \mathrm{K}^{+}$, and $\mathrm{H}^{+}$ transport, and root-cell membrane potentials. Plant Physiol., 91:1188-1196, 1989.

MORONI, J.S.; SCOTT, B.J. \& WRATTEN, N. Differential tolerance of high manganese among rapeseed genotypes. Plant Soil, 253:507-519, 2003.
MUNNS, D.N.; JACOBSON, L. \& JOHNSON, C.M. Uptake and distribution of manganese in oat plants II. A kinetic model. Plant Soil, 19:193-204, 1963.

NOORDWIJK, M.V. \& FLORIS, J. Loss of dry weight during washing and storage of root samples. Plant Soil, 53:239243,1979 .

PAGE, E.R. \& DAINTY, J. Manganese uptake by excised oat roots. J. Exp. Bot., 15:428-443, 1963.

REID, R. \& HAYES, J. Mechanisms and control of nutrient uptake in plants. Inter. Rev. Cytol., 229:73-114, 2003.

ROUT, G.R.; SAMANTARAY, S. \& DAS, P. Studies on differential manganese tolerance of mung bean and rice genotypes in hydroponic culture. Agronomie, 21:725-733, 2001.

SAS Institute. SAS/STAT. User's guide, version 6.11. 4.ed. Cary, Statistical Analysis System Institute, 1996. v.2. 842p.

TSUKAMOTO, T.; NAKANISHI, H.; KIYOMIYA, S.; WATANABE, S.; MATSUHASHI, S.; NISHIZAWA, N.K. \& MORI, S. ${ }^{52} \mathrm{Mn}$ translocation in barley monitored using a positron-emitting tracer imaging system. Soil Sci. Plant Nutr., 52:717-725, 2006.

WANG, J.J. Kinetics of manganese uptake by excised roots of sensitive and tolerant tobacco genotypes. J. Plant Nutr., 26:1439-1450, 2003.

YANG, W.E.; BALIGAR, V.C.; FOSTER, J.C. \& MARTENS, D.C. Accumulation and transport of nickel in relation to organic acids in ryegrass and maize grown with different nickel levels. Plant Soil, 196:271-276, 1997. 